\title{
Filosofia da Educação não formal e Complexidade na intervenção comunitária
}

\author{
Ines Saavedra ${ }^{1}$ \\ Clara Costa Oliveira ${ }^{2}$
}

\section{Resumo:}

Os princípios emancipatórios da filosofia de educação atual, enquadrados no paradigma da complexidade e de educação ao longo da vida, incitou-nos a escrever este documento. $O$ foco será a compreensão da vinculação a um paradigma e das suas consequências teóricas e metodológicas, demonstrando especificamente como tal se concretiza na investigação-ação enquadrada no paradigma da complexidade, teorizando em educação não formal e intervenção comunitária. Procuramos, assim, tecer um enquadramento que mostre como a investigação-ação e métodos associados se coadunam neste tipo de pesquisa e intervenção em filosofia de educação não formal.

Palavras-chave: Educação não formal. Epistemologia. Complexidade

\begin{abstract}
:
The emancipatory principles of current education philosophy, framed in the paradigm of complexity and lifelong education, prompted us to write this document. The focus will be on understanding the link to a paradigm and its theoretical and methodological consequences, specifically demonstrating how this is concretized in action research framed in the paradigm of complexity, theorizing in non-formal education and community intervention. Thus, we seek to weave a framework that shows how action research and associated methods fit into this type of research and intervention in non-formal education philosophy.
\end{abstract}

Keywords: Non-formal education. Epistemology. Complexity

\section{Introdução}

$\mathrm{Na}$ filosofia da educação contemporânea muitos autores se têm preocupado com a fundamentação da educação não formal, bem como com a intervenção dentro de comunidades, num esforço de ser útil à

\footnotetext{
${ }^{1}$ Mestre em Educação de Adultos e Intervenção Comunitária e Mestre em Física

${ }^{2}$ Universidade do Minho, Portugal
} 
transformação pessoal e social usualmente mais vinculada a outras áreas do saber, como a psicologia e sociologia da educação.

O carácter diferenciador da filosofia da educação face a outras áreas é importante por permitir uma visão mais ampla e integradora do saber humano, que não só a científica, articulando esta a outros modos de vida (WITTGENSTEIN, 1988) muito importantes no quotidiano que se quer transformador, de acordo com diretrizes da ONU solicitadoras de contributos efetivos para um desenvolvimento sustentável (UNESCO, s/d) num momento tão conturbado da história humana.

A falta de rigor epistêmico e epistemológico que encontramos tantas vezes em textos de estas áreas, nomeadamente na questão metodológica, incitou-nos a escrever este documento, acreditando que podemos melhorar essa situação. O nosso foco será a compreensão da vinculação a um paradigma e das suas consequências teóricas e metodológicas que deverão permear toda a pesquisa e intervenção, demonstrando especificamente como tal se concretiza na investigação-ação enquadrada pelo paradigma da complexidade, onde nós nos situamos e agimos teorizando em educação não formal e intervenção comunitária. Para tal, começaremos por um esclarecimento sobre o paradigma que sustenta a nossa intervenção e investigação. A partir da base apresentada adentrar-nos-emos pelos conceitos de educação não formal e intervenção comunitária, pretendendo uma compreensão mais complexa destes processos. Procuramos, assim, tecer um enquadramento que mostre como a investigação-ação e métodos associados se coadunam neste tipo de terreno de pesquisa e intervenção.

Este texto tem por base um trabalho de Mestrado em Educação de adultos não formal e intervenção comunitária pela primeira autora (não publicado) e supervisionado cientificamente pela segunda autora ${ }^{3}$.

\section{Todos trabalhamos inseridos num paradigma}

O conceito de paradigma, criado por Thomas Kuhn na obra Estrutura das Revolução Científicas em 1962, tem sido alvo de diversas conceptualizações

${ }^{3}$ SAAVEDRA (2018), acesso disponível em: http://hdl.handle.net/1822/59719 
e críticas. Kuhn definiu-o como uma representação que é partilhada por uma comunidade científica, pressupondo premissas, pré-conceitos e métodos, que condicionam quais as questões mais relevantes na produção de conhecimento e a melhor forma de lhes responder. Quando surgem dificuldades na resolução destas questões é originada uma crise que leva lentamente à criação de um novo paradigma, que se caracteriza por uma mudança descontínua, um progresso por saltos, ou seja, uma revolução científica (FILHO, 2014), (KUHN, 1970, 1977).

Boaventura de Sousa Santos (2008) chama a atenção, contudo, para o fato de Kuhn ter construído o caráter "pré-paradigmático", onde existe um debate constante, contrapondo-se ao consenso paradigmático que marcou as ciências naturais. Assim, segundo Kuhn, as ciências sociais estariam numa fase menos desenvolvida e atrasada relativamente às ciências naturais. Por este motivo, Santos (2008) aconselha que o caráter "pré-paradigmático" das ciências sociais, na conceção de Kuhn, seja abandonado ou revisto de forma profunda.

Afastando-se da conceção de paradigma formulada por Kuhn (BARROS, 2010), Morin propõe uma definição que designa o "conjunto de relações fundamentais entre associações e/ou oposições dentro de uma série de noções-relações mestres que comandam ou controlam os pensamentos, discursos e teorias" (MORIN, 1992, p. 372). Esta definição de paradigma será usada neste texto e permite compreender o paradigma da complexidade como estando aberto a desafios atuais da educação não formal, derivados, em grande parte, das tecnologias de informação, nomeadamente advindos da cibernética (PREDBORSKA, 2013). Uma forma de pensar complexa pode facilitar, também, processos de atuação e intervenção mais complexos perante estes desafios - como se procurará averiguar de seguida.

Inquietado pelos problemas ou realidades se terem tornando cada vez "mais multidisciplinares, transversais, multidimensionais, transnacionais, globais e planetários" Morin (2000, p. 36) defendeu que se deveria superar a dispersão do conhecimento que se encontra fragmentado nas mais diversas áreas. Assim, o paradigma da complexidade teve como base a combinação 
de várias teorias, como por exemplo: a teoria geral de sistemas, teorias de cibernética, biologia, física e química, teorias da comunicação, teoria da autopoiesis (STENGERS, 1985), (PREDBORSKA, 2013), (SERVA, 1992), etc.

A complexidade, e não complicação (MORIN, 1992), (OLIVEIRA, 2017), tem origem na palavra latina complexus, que significa o que foi tecido junto:

[...] há complexidade quando elementos diferentes são inseparáveis constitutivos do todo (como o económico, o político, o sociológico, o psicológico, o afetivo, o mitológico), e há um tecido interdependente, interativo e inter-retroativo entre o objeto de conhecimento e seu contexto, as partes e o todo, o todo e as partes, as partes entre si. Por isso, a complexidade conecta a unidade e a multiplicidade (MORIN, 2000, p. 38).

Assim, para este autor, o ser humano e a sociedade são unidades complexas (interconectadas continuamente) que se caracterizam pelas suas multidimensionalidades. Relativamente ao ser humano, salienta as suas dimensões (distinguíveis apenas para um observador, tal como salientado por Oliveira (2017) de acordo com o segundo princípio da teoria da autopoiesis: biológica, psíquica, social, afetiva, racional; analogamente, para a sociedade, destaca as dimensões: histórica, econômica, sociológica, religiosa, entre outras. Para o autor, a educação deve estimular um conhecimento pertinente que passa por reconhecer a complexidade, assumindo o seu caráter multidimensional.

Este paradigma vem, assim, assumir a rede rizomática (DELEUZE; GUATTARI, 1980) das relações e dos fenômenos. Um pensar complexo reconhece a existência de movimento, incertezas, riscos e fatores desconhecidos, em qualquer processo de investigação/intervenção. Distingue-se, portanto, da investigação clássica, que unifica (reduz) o que é múltiplo, quantifica (separa) o que é qualificável, simplifica o que é complexo, para tornar o objeto/sistema de estudo facilmente manipulável e conhecido (ALHADEFF-JONES, 2009, 2010), (MORIN et al, 2003). A 
investigação em complexidade promove, pelo contrário, interpretações a partir do local e do singular, valoriza a referência à história em qualquer descrição ou explicação, estuda a situação social, econômica e política de um dado contexto, reconhece a impossibilidade de isolar unidades elementares únicas e, como tal, a necessidade de vincular o conhecimento de qualquer elemento ao conhecimento das partes a que pertencem, assumindo-se que o todo nunca é igual à soma das partes (ALHADEFFJONES, 2010), (MORIN, 1992, 2000), (OLIVEIRA, 2017).

A complexidade desafia a forma como o conhecimento é construído, pois implica repensar constantemente sobre resultados obtidos. Os/as investigadores/as devem questionar, por exemplo, a natureza heterogênea dos referenciais utilizados e a forma como a sua própria experiência ecoa com a vida daqueles/as com quem estão a interagir e vice-versa. Adicionalmente, de forma a conseguir estimular processos de transformação individuais e coletivos no público com o qual se está a trabalhar, é importante que educadoras/es sejam capazes de se desenvolver complexamente ao longo dos seus percursos acadêmico e profissional. Torna-se, por isso, necessário que a pessoa que investiga desenvolva um processo permanente de autorreflexão (ALHADEFF-JONES, 2009), (OLIVEIRA, 2007).

Um conjunto de teorias que são integradas no paradigma da complexidade é conhecido como Movimento da Auto-Organização (MAO), que englobam teorias minoritárias dentro das usas áreas disciplinares, desde a Física (teoria das estruturas dissipativas; PRIGOGINE; STENGERS, 1993) à Teologia Girardiana (GIRARD, 1978, entre muitos outros). Possuem traços formais comuns, pois nelas se descreve a capacidade de selecionar e de descartar determinadas perturbações do ambiente, desenvolvendo desorganizações às quais se seguem reorganizações internas, por exemplo (SERVA,1992); outras características são descritas em Oliveira (1999) e Dupuy e Dumouchel (1983), entre outros.

\subsection{Teorias auto-organizativas e educação não formal}


O conhecimento de padrões ${ }^{4}$ auto-organizativos é essencial para o/a educador/a relativamente a ele/a mesmo/a e ao/à educando/a, quando nos situamos dentro deste quadro epistêmico. De fato, qualquer educador/a deve saber identificar o seu próprio padrão auto-organizativo (BATESON, 1972; OLIVEIRA, 2013b) pois desta forma pode compreender como ocorreu o seu processo de aprendizagem ao longo da sua vida, podendo mais facilmente colocar-se no lugar do/a educando/a. Por outro lado, quando a relação existente entre educador/a e educando/a é de confiança, o/a educando/a pode manifestar a sua auto-organização. Neste sentido, as histórias de vida e as narrativas escritas são exemplos de métodos utilizados para aceder aos padrões auto-organizativos de si próprio e dos/as outros/as no âmbito de uma educação permanente e comunitária (RIBEIRO-DIAS, 2009), (OLIVEIRA, 2017, entre outros). O/a educador/a, ao ter acesso àquilo que ele observa e assume (ou não) como sendo o padrão auto-organizativo do/a educando/a, pode, por um lado, facilitar ao/à educando/a o entendimento da forma como este/a atribui sentido(s) ao mundo e/ou, por outro lado, adequar a forma como provoca a construção de conhecimentos ao/à educando/a. Se conseguir ir ao encontro dos padrões de compreensão do mundo do/a educando/a, este/a será capaz de transformar a informação em aprendizagem (OLIVEIRA, 2008, 2017).

Uma das teorias mais divulgadas no seio do movimento da autoorganização (MAO) é a teoria autopoiética, ou da autopoiesis, de Humberto Maturana e Francisco Varela (2003), sobre a qual nos iremos debruçar devido à sua complexidade holista (OLIVEIRA, 2013a). A pertinência desta no âmbito de processos de educação não formal e intervenção comunitária deve-se ao fato de esta teoria poder contribuir para uma compreensão complexa dos processos de educação e aprendizagem pois, como evidenciado por Gadotti (2005, p. 43) "só aprendemos quando nos envolvemos profundamente naquilo que aprendemos, quando o que estamos aprendendo tem sentido para as nossas vidas. 'Conhecer e aprender são processos autopoiéticos"”. Os seres humanos são designados por Maturana e

\footnotetext{
4 O conceito "padrão" indica o caráter autorregulador dos sistemas vivos e das suas produções (OLIVEIRA, 2017).
} 
Varela por máquinas autopoiéticas (MATURANA; VARELA, 2003). Máquinas, porque se adota uma visão mecanicista da biologia ${ }^{5}$ dos sistemas vivos (onde os fatores que afetam a organização dos sistemas são processos físico-químicos, e não de índole vitalista) e autopoiéticas, porque os sistemas vivos são sistemas de autoprodução complexificada (MATURANA; VARELA, 2003), (OLIVEIRA, 2013a, 2017).

Para melhor compreender o funcionamento dos seres autopoiéticos (que podem ser encarados como um organismo ou um ou mais sistemas orgânicos, acoplados estruturalmente) e como este afeta os processos de aprendizagem e/ou educação, vamos posicionar-nos num referencial que se encontra, ora no próprio organismo, ora num observador externo ao organismo.

Se nos posicionarmos no referencial do próprio organismo podemos concluir que um organismo possui unicamente estados internos. A organização formal de um ser vivo é fechada (não confundir com isolada, onde não existem trocas entre o "interior" e o "exterior"), o que significa que os organismos vivos selecionam, transformam e eliminam componentes físico-químicos devido à sua autopoiesis (ou padrão auto-organizativo, em linguagem batesoniana). Um outro aspecto a ter em consideração é a dimensão comunitária que, pelo fato de ser biológica (ou seja, esta dimensão não é algo exterior, a não ser de um ponto de vista observacional), é essencial para a produção e manutenção da significação do organismo. Neste sentido, também as perturbações do meio comunitário dos organismos vivos são selecionadas (esta seleção é o que permite a diferenciação entre comunidade e sociedade para um ser vivo), no sentido da conservação do seu padrão auto-organizativo (MATURANA; VARELA, 2003), (OLIVEIRA, 2013b). A questão da aprendizagem, que é um estado interno, de um organismo é um fator essencial a ter em consideração pois "aprender é viver" - que é o primeiro postulado da teoria da autopoiesis (OLIVEIRA, 2017).

\footnotetext{
5 A biologia mecanicista afirma-se contra o vitalismo na biologia, e não deve ser confundida com o mecanicismo da Física (OLIVEIRA, 2017).
} 
No segundo referencial mencionado, o do (auto)observador, existem estados internos e externos de um organismo. As perturbações (observacionalmente) externas são transformadas em estados físicoquímicos que os organismos produzem consoante a sua autopoiesis. Estas perturbações são variadas, podendo destacar-se, nomeadamente, os atos educativos e as interações comunicativas com outros organismos que partilham espaços comuns (família, colegas, profissionais, etc.). Na primeira situação, os atos educativos (encarados como estados externos nesta perspectiva) podem contribuir para a complexificação e uma aprendizagem dos organismos, podendo ocorrer fenômenos de aprendizagem-educação. Relativamente ao segundo ponto, salienta-se a complexificação do ser humano através do acoplamento com outros seres vivos, que contribuem para a construção de sentidos para o e no mundo (OLIVEIRA, 2017). Em sistemas de organismos acoplados, os seres vivos têm de:

Aprender a viver: 1) articulando as várias e contínuas perturbações advindas dos acoplamentos estruturais com a manutenção e conservação do seu padrão auto-organizativo; 2) terão que saber articular a sua autopoiesis específica com o padrão auto-organizativo do sistema maior do qual fazem parte, e que resulta dos acoplamentos empreendidos. (OLIVEIRA, 2017, p. 8).

A teoria da autopoiesis tem como $2^{\mathrm{a}}$ postulado: "tudo o que é dito é dito por um observador", reconhecendo que não há observadores/as neutros/as. Significa, assim, que as crenças, a história de vida, a ética, o paradigma científico cultural, etc., sob o qual um/a dado/a observador/a cientista se move, influenciam as explicações científicas por este/a produzidas. É, por isso, importante que este/a observador/a consiga identificar o conjunto de fatores que o/a levam a uma dada conclusão (OLIVEIRA, 2007, 2013, 2017).

2. Educação permanente para o Desenvolvimento Sustentável, pela intervenção comunitária

Embora a utilização do conceito de "Educação ao Longo da Vida" tenha aparecido pela primeira vez em 1919, num documento oficial em Inglaterra 
(sob a forma de "Lifelong Education", tendo sido traduzido para francês por "Éducation Permanente"), a ideia de uma educação continuada ao longo da vida já fazia parte das concepções/práticas educativas de Platão (na Academia), Coménio (PIAGET, 2010), de Iluministas, como Voltaire (GADOTTI, 2016), entre outros. No entanto, a Educação Permanente (da tradução francesa "Éducation Permanente") ou a Educação ao Longo da vida (da tradução inglesa de Life-long Education and Learning) começou a ganhar um corpo teórico mais elaborado entre os anos 60 e 70 do séc. XX (LIMA, 2016a), (NÓVOA, 2009). De fato, a “educação é permanente" pois, sendo o ser humano inacabado e consciente desta condição, tem a necessidade de um "permanente processo de busca e de reinvenção do próprio mundo e de si mesmo" (FREIRE, 2000, p. 49).

\subsection{Educação Permanente}

Como resposta à "crise mundial de educação" (1968), que provinha de um desfasamento dos sistemas educativos relativamente às novas exigências do sistema capitalista, a Educação Permanente apresentou-se como referencial para a educação do futuro de então (CANÁRIO, 1999), (GADOTTI, 2016). Para tal foi preponderante o relatório da UNESCO, sob o título "Aprender a Ser” presidido e coordenado por Edgar Faure (1973), considerado uma das contribuições mais influentes para a Educação Permanente (CAMOZZATO; COSTA, 2017), (GADOTTI, 2016), (LIMA, 2007), (NÓVOA, 2009). Neste documento, Faure (1973) demonstra como concebe esta reinvenção da educação:

¿No ha llegado el momento de exigir algo muy distinto a los sistemas educativos? Aprender a vivir; aprender a aprender, de forma que se puedan ir adquiriendo nuevos conocimientos a lo largo de toda una vida; aprender a pensar de forma libre y crítica; aprender a amar el mundo y a hacerlo más humano; aprender a realizarse en y mediante el trabajo creador. (FAURE, 1973, p. 132).

A Educação Permanente pressupõe, assim, o direito de cada ser humano se realizar plenamente, de participar na construção do seu próprio futuro, de se poder expandir em toda a sua complexidade (enquanto indivíduo, 
cidadão, membro de uma família e de uma comunidade, enquanto "inventor de técnicas e criador de sonhos" (FAURE, 1973, p. XX). É, portanto, um processo de crescimento holístico que ocorre em todas as idades, desde o nascimento até à morte. Reconhecendo a sociedade em mudança constante, a Educação Permanente tem como objetivo, mais do que proporcionar conhecimentos, tornar as pessoas capazes de detectarem as suas necessidades e para elas encontrarem resposta. Pretende-se, assim, que o indivíduo, através da sua educação, seja capaz de enfrentar os constantes desafios provenientes de uma sociedade em frequente modificação (CAMOZZATO; COSTA, 2017), (CANÁRIO, 1999), (MELO, 2011), (NÓVOA, 2009), (RIBEIRO-DIAS, 2009).

Gelpi (1998) chamou a atenção para as vertentes de transformação social da Educação Permanente, apelando à valorização e incentivo à politização e à construção de uma sociedade mais participada, justa e igualitária (LIMA, 2007, 2016b), (MELO, 2011).

A Educação Permanente procura, então, uma articulação horizontal entre as aprendizagens efetuadas em meio formal, não formal ou informal. É de destacar que: (i) as aprendizagens não se fazem no isolamento mas na relação com o próprio, com outras pessoas e outros seres vivos, com o mundo físico e os seus objetos; (ii) que os processos de aprendizagem não têm necessariamente uma via única e com vista a atingir um aperfeiçoamento; (iii) estes são reversíveis, paralisam e retrocedem, constantemente. Além disso, a Educação Permanente salienta a importância da sociedade e das suas estruturas políticas e institucionais, no sentido de apoiarem, defenderem e estimularem os referidos processos de aprendizagem e o desenvolvimento de capacidades e aspirações (MELO, 2011). Estas concepções de Educação Permanente são entendidas como um projeto de humanização e de transformação social (LIMA, 2016b).

Em 1996, a concepção de Educação Permanente formulada no Relatório “Educação: Um Tesouro a Descobrir" passa a ser sustentada em quatro pilares: aprender a conhecer, aprender a conviver, aprender a fazer e aprender a ser (DELORS, 1996). Para Lima (2007) este é um dos poucos 
documentos de circulação internacional que recusa "discursivamente orientações totalmente economicistas ou exclusivamente pragmáticas" (p. 23). Contudo, segundo Gadotti (2016), o foco deixa de ser a educação e passa a ser o da aprendizagem. Para este autor, o relatório afasta-se das referências humanistas (como a participação e cidadania democráticas) que marcaram o relatório Faure (1973), em favorecimento de uma visão instrumental, com base nas exigências do mercado - ainda que não de forma claramente assumida (GADOTTI, 2016), (MELO, 2011).

Progressivamente, a "educação permanente ou ao longo da vida" (formulada nos anos 60 a 70) passou a ser substituída, nas suas políticas e práticas, pelos conceitos de "formação e aprendizagem ao longo da vida", no sentido de aprendizagem profissional (LIMA, 2007), (LIMA, 2016a). Esta substituição deve-se, em grande parte, aos modelos de políticas sociais que vigoraram ou vigoram, aquando da utilização destes conceitos. Enquanto no primeiro conceito a educação é compreendida como um direito (num contexto de Estado-Providência), no segundo conceito é encarada como um serviço (contexto político neoliberal). Convém relembrar que num regime político neoliberal, o Estado desresponsabiliza-se de uma série de fenômenos (como a educação, a saúde, o emprego, a pobreza e exclusão social), passando estes a ser considerados unicamente da responsabilidade individual. No caso específico da educação, ou concretamente da formação e a aprendizagem ao longo da vida, apelam-se às responsabilidades individuais para realizar aprendizagens no sentido de adquirir “competências para competir", para ganhar vantagens no mercado de trabalho (GADOTTI, 2016), (LIMA, 2007).

A Educação Permanente foi, portanto, "esvaziada" do seu sentido original (GADOTTI, 2016), confundindo-se com os seguintes processos: “escolarização permanente, educação escolar de segunda oportunidade, reconhecimento e certificação de competências, formação profissional contínua, vocacionalismo adaptativo e funcional, inclusão social para as periferias ou margens de dentro de um sistema [...]" (LIMA, 2016b, p. 56). Estes processos representam os sistemas educativos e de educação 
permanente regidos por um modelo de produção industrial que, como alertou Ivan Illich, haviam de resultar em "[...] instrumentos de condicionamento, poderosos e eficazes, que produzirão em série uma mão de obra especializada, consumidores dóceis, usuários resignados" (ILLICH, 1976, p. 8). Assim, esta Educação Permanente, em vez de ser usada para descobrir e potenciar a criatividade e capacidades dos indivíduos, pode ser usada para a sua manipulação (LIMA, 2016b), podendo constituir um instrumento de opressão e dominação.

Dado o contexto histórico e socioeconômico atual, em parte denunciado no parágrafo anterior, considera-se pertinente ressalvar a perspectiva de Melo que mostra que:

[...] A Educação Permanente tem um papel essencial a cumprir, na resistência aos novos veículos de opressão e na invenção de alternativas liberatórias. A Educação Permanente, tal como foi desenhada e teorizada nas décadas de 60 e 70 do século passado, torna-se agora fundamental para formar cidadãos, mais informados, mais confiantes, mais inventivos, garantindo assim as condições subjectivas e culturais de uma sociedade mais aberta e plural, mais criativa e participativa (MELO, 2011, p. 8).

\subsection{Intervir em/com comunidades}

A Intervenção Comunitária tem sido parte integrante de agendas ao nível da: promoção de saúde, prevenção de certas práticas e/ou comportamentos, psicologia comunitária (TRICKETT et al, 2011), etc. Tendo por base uma perspectiva pedagógica da intervenção comunitária (ANDRADE, 2013), esta pode ser interpretada como o conjunto de ações que visam promover o desenvolvimento de uma comunidade ${ }^{6}$ através da sua participação ativa, procurando a transformação da sua própria realidade (SÁNCHEZ, 2011), (GARCÍA; SÁNCHEZ, 1997). Para Lapalma (2001) a intervenção

\footnotetext{
${ }^{6}$ Existem vários conceitos de comunidade. Um que se encontra associado ao conceito de empoderamento assume que uma comunidade se caracteriza pelos pontos seguintes: (i) associação/filiação (com sentido de identidade e de pertença); (ii) sistemas de símbolos comuns (com linguagem, rituais e cerimónias próprias); (iii) valores e normas compartilhados; (iv) influência mútua (os membros da comunidade têm influência e são influenciados uns pelos outros); (v) necessidades compartilhadas e compromisso de atendêlas; (vi) conexão emocional partilhada (onde os membros partilham histórias e experiências comuns e apoiam-se mutuamente) (ISRAEL et al, 1994).
} 
comunitária tem um papel particularmente importante junto de comunidades marginalizadas ou socialmente excluídas, referindo que esta passa por:

Procesos intencionales de cambio, mediante mecanismos participativos tendientes al desarrollo de recursos de la población, el desarrollo de organizaciones comunitarias autónomas, a la modificación de las representaciones de su rol en la sociedad y sobre el valor de sus propias acciones para ser activo en las condiciones que las marginan y excluyen. (LAPALMA, 2001, p. 62).

Um aspecto importante é a identificação das necessidades da comunidade com que se está a desenvolver o processo de intervenção. Estas podem passar por: (i) garantir necessidades básicas (alimentação, saúde, habitação); (ii) aumentar o nível de vida (com uma educação de qualidade, trabalho, cultura, prevenir fatores de risco, como toxicodependência, violência, etc.) ou contribuir para um sentido de comunidade que proporcione convívio (que é uma carência nos dias que correm, devido ao individualismo a que a globalização conduziu); (iii) levar a condições de empoderamento (principalmente com públicos que têm ausência de poder sobre as suas próprias vidas, como é o caso daqueles/as que sofrem de marginalização e/ou exclusão social) (CABEZAS et al, 2017), (GARCÍA; SÁNCHEZ, 1997), (HOMBRADOS-MENDIETA; GÓMEZ-JACINTO, 2001), (LAPALMA, 2001), (MARCHIONI, 1999), (ÚCAR, 2009).

Através de ciclos de prática e reflexão participativos ao longo de todo o processo, pretende-se desenvolver a autonomia, a capacitação, o fortalecimento e a tomada de decisões da comunidade, no sentido de facilitar a autogestão da mesma (ANDRADE, 2013), (CABEZAS et al, 2017), (SÁNCHEZ, 2011).

O processo de intervenção comunitária pretende-se integrado, coordenado e globalizado, isto é, deve estar inserido num projeto mais amplo, de forma a promover a sustentabilidade global (GARCÍA; SÁNCHEZ, 1997), visando objetivos presentes na resolução da Organização das Nações Unidas "Transformar o nosso mundo: Agenda 2030 de Desenvolvimento Sustentável”. Esta resolução entrou em vigor a 1 de janeiro de 2016, foi aprovada por 193 Estados-membros da ONU e tem 
como propósito ser implementada até 2030 (UNESCO, s.d.; UNRIC, 2016). É constituída por 17 objetivos, para os quais se estipularam 169 metas. Estes objetivos e metas procuram ser um meio para o desenvolvimento sustentável a várias dimensões (social, econômico, ambiental), procurando erradicar todas as formas de pobreza, promover a paz, a justiça e instituições eficazes (UNRIC, 2016). No contexto da filosofia da educação temos, porém que questionar estas metas como um catálogo de «metavirtudes» (BURBULES, 2020), no qual a vontade de poder neoliberal se esconde.

\section{Metodologia e métodos interventivos em educação não formal}

Face ao acima exposto, temos vindo a empreender utilizar, e a construir, investigação-ação como metodologia mais consonante com uma filosofia da educação ancorada no paradigma da complexidade.

A criação do conceito de investigação-ação é normalmente atribuída a Kurt Lewin (1946). Existem, contudo, autores que referem que a investigação sobre a prática com o intuito de a melhorar, noção subjacente à metodologia de investigação-ação, é bastante antiga, tendo sido utilizada, inclusive, por John Dewey (1933) ou por antigos empiristas gregos (TOLEDO; JACOBI, 2013), (TRIPP, 2005).

A investigação-ação tem sido alvo de diversas conceitualizações, derivadas, essencialmente, dos diferentes interesses que orientam a investigação. Estes manifestam-se, consequentemente, em aplicações e áreas variadas, tais como: educação, desenvolvimento comunitário, serviço social, administração e organização de empresas, economia, política, agricultura, saúde, tecnologia, entre outras (MCNIFF; WHITEHEAD, 2006), (PERUZZO, 2016), (TOLEDO; JACOBI, 2013).

Em termos ontológicos, assume-se que o/a investigador/a está em relação com o que se encontra no campo da investigação, não sendo um/a mero/a espectador/a, mas um/a participante ativo/a. Considera-se, portanto, que influencia e é influenciado/a pelos/as restantes participantes. Assume-se, ainda, que a investigação não é neutra, regendo-se, em parte, pelos valores 
do/a investigador/a (MCNIFF; WHITEHEAD, 2006), (TOLEDO; JACOBI, 2013).

Em termos epistemológicos, o "objeto" da investigação-ação não são outras pessoas, mas o "eu" em relação a outros "eus". Este "eu” não é uma entidade isolada, já que, como referido acima, o/a investigador/a encontra-se em relação com os/as participantes, preferencialmente em acoplamento estrutural, dentro de unidades compostas (OLIVEIRA, 1999). Assim, a criação de conhecimento/mudança é um processo colaborativo, pois a investigação-ação implica trabalhar com outros em todas as fases do processo. Adicionalmente, assume-se que o conhecimento construído é sujeito a tentativas e erros. Este é também incerto, pelo fato de uma questão poder levantar várias respostas, sendo que estas estão constantemente abertas a alterações (GREENWOOD; LEVIN,2007), (MCNIFF; WHITEHEAD, 2006).

A pessoa que realiza a investigação-ação não é considerada uma especialista externa que faz investigação em pessoas, como já referido, mas uma pessoa que pesquisa com (e para) um dado público. O objetivo da investigação é assim, essencialmente, orientado pelas preocupações deste público, no sentido de solucionarem problemas e de melhorarem os seus contextos envolventes (GREENWOOD; LEVIN, 2007), (MCNIFF; WHITEHEAD, 2006), (LATORRE, 2003). Neste processo de colaboração e participação das pessoas participantes reconhece-se e encoraja-se a troca de, e a produção de novos, conhecimentos (LATORRE, 2003), (TOLEDO; JACOBI, 2013).

A investigação-ação incita os/as investigadores/as a investigar e a avaliar o seu trabalho individual e coletivo (uma vez que são investigadores/asparticipantes), de uma forma contínua. Iniciando-se com a identificação de algo que constitui um problema para uma pessoa/comunidade, o processo prossegue com ações, previamente discutidas e planificadas entre todos os intervenientes, que se acredite resolverem, ou melhorarem, a situação. Exige-se, porém, uma constante reformulação da intervenção (o que denota o caráter cíclico deste processo), de forma a atender às necessidades 
coletivas, que vão surgindo, e alterando-se face a cada ação empreendida. Daí a premente necessidade de todos os passos serem continuamente avaliados e ajustados, numa dimensão complexa e exigente.

Assim, a investigação-ação consiste em um processo que, para além de ser flexível e interativo, é constituído pelas fases de ação-reflexão, de um modo contínuo (e não por etapas sequenciais): (i) observar; (ii) refletir; (iii) agir; (iv) avaliar; (v) modificar; (vi) mover em novas direções. Esta interrelação cíclica entre ação e investigação é a base para uma possível transformação social do contexto onde se está a desenrolar a investigação (MCNIFF; WHITEHEAD, 2006), (LATORRE, 2003), (TOLEDO; JACOBI, 2013).

Esta metodologia investigativa pressupõe a criação de ideias e conhecimento sobre, por um lado, as suas práticas (como as coisas podem ser feitas e o porquê) e, por outro, as suas aprendizagens e a do público com quem desenvolve este processo de investigação. Distancia-se, assim, de metodologias tradicionais de investigação de ciências sociais, nas quais investigadores/a produzem teoria, que será aplicada na prática por um/a educador/a, facilitador/a ou dinamizador/a (MCNIFF; WHITEHEAD, 2006).

De ressaltar que a avaliação de um projeto de intervenção social é considerada um tipo específico de investigação, denominado "investigação avaliativa", que recorre a métodos e técnicas da investigação social (ANDER-EGG, 2011), (MINAYO, 2009). Podendo a avaliação ser externa (quando uma equipa, por exemplo, é contratada para avaliar um programa ou projeto de uma instituição) ou interna (realizada pelos/as autores/as do próprio programa ou projeto) (GUERRA, 2002), (MINAYO, 2011), a investigação avaliativa é coerente com a metodologia de investigação-ação uma vez que pressupõe a melhoria das condições sociais (ANDER-EGG, 2011), (GUERRA, 2002), (MINAYO, 2011).

Neste tipo de investigação há fortes recomendações para se recorrer à triangulação, pois esta permite "olhares múltiplos e diferentes do mesmo lugar de fala" (TUZZO; BRAGA, 2016, p. 156), refletindo aspectos da 
teoria da complexidade que, segundo Minayo, Souza, Constantino e Santos (2005) devem ser tidos em conta ao longo deste processo.

De acordo com os interesses que norteiam este tipo de investigação, Carr e Kemmis (2004) distinguiram três tipos de investigação-ação: (i) investigação-ação conduzida por um interesse técnico em melhorar o controlo sobre os resultados (é o caso, por exemplo, de um estudo de Lewin que pretendia encorajar, durante a $2^{\mathrm{a}}$ Guerra Mundial, os civis americanos a comerem os órgãos dos animais, de forma a que a restante carne fosse enviada aos soldados americanos (KEMMIS et al, 2014)); (ii) investigaçãoação guiada por um interesse em melhorar as práticas dos/as educadores/as, de forma a facilitar as aprendizagens dos/as educandos/as; (iii) investigaçãoação crítica orientada pelo interesse em emancipar pessoas, promovendo a reflexão destas e a transformação dos seus contextos de uma forma mais sustentável e justa (KEMMIS et al, 2014), (MCNIFF; WHITEHEAD, 2006). Esta última pode identificar-se com a investigação-ação participativa (IAP) (ANDER-EGG, 2003), (FALS-BORDA, 1991), (HOLLIDAY, 2012), sendo que alguns autores utilizam o termo de investigação-ação (KEMMIS et al, 2014) com o sentido acima descrito, enquanto outros preferem investigação participativa (ERASMIE, 1983), (GARCÍA et al, 2015), (LIMA, 1990).

\section{Métodos}

A revisão da literatura em investigação-ação é um método especialmente importante por dar acesso a experiências de intervenção com objetivos, e contexto, similares aos nossos. Precisamos, porém, de fazer a sua busca tendo em conta o paradigma da complexidade e tudo o que daí decorre, para não incorrermos em incongruências epistemológicas, que invalidam toda e qualquer forma de conhecimento.

Visando a inserção como um par com a população-alvo, os investigadores devem ser bons observadores, com treino não verbal, saber calar e agir quando necessário, a simultâneo. Esta linhagem de investigação assenta no holismo epistemológico (RORTY, 1979), pelo que o uso de 
grelhas de observação terá que ser ajustado ao paradigma e metodologia que lhes subjazem. Tal surge muitas vezes como algo irreal face a outros tipos de investigação, mas consegue-se com recurso a métodos adequados (no qual usualmente incluímos diários de bordo) e até a «não métodos» (HERNÁNDEZ-HERNÁNDEZ, 2019), como conversas informais, quando já nos tornamos mais um entre uma comunidade. Implica, pois, um envolvimento emocional alicerçado em treino de gestão emocional.

Além destes métodos e técnicas, a escrita amiúde de narrativas pelos investigadores (e seus supervisores, se existirem) potencia o autoconhecimento e reconhecimento de padrões autopoiéticos e sua (não) articulação com padrões comunitários, alicerçados em regras usualmente não verbais de comunicação (seguindo coerentemente G. Bateson em OLIVEIRA, 2013b).

Conhecer os outros via narrativas, histórias de vida, entrevistas semiabertas com guião, grelhas qualitativas de comunicação não verbal, são modos de acoplamento estrutural fundamentais. O mesmo se aplica à utilização de diário de bordo e conversas informais.

Trabalhar com pessoas na resolução de problemas possibilita-nos propor e aceitar inovação, num empoderamento efetivo de todos os implicados, inclusive via animação promotora de alegria, descoberta e criatividade (HUIZINGA, 1971).

\section{Conclusões}

A utilização do paradigma da complexidade ainda exige a sua fundamentação epistemológica dado, até agora, não ser utilizado com frequência, ou por o ser de modo inadequado. Pelas mesmas razões, a triangulação entre revisão de literatura, dados obtidos na investigação-ação e fundamentação teórica fornecem uma consistência investigativa rigorosa, indispensável em filosofia da educação.

Assis, Njaine, Minayo e Santos (2005) reforçam a importância da existência de uma apreciação interpares nas investigações avaliativas, pelo que a avaliação final, para além de ter em conta dados produzidos pelo 
investigador-agente (por observação participante, diário de bordo e autonarrativa, por exemplo), devem contar também com apreciações de supervisores, quando os há (via entrevista semiestruturada, por exemplo), bem como com dados obtidos pela apreciação dos agentes que não os investigadores e supervisores, de modo anônimo e confidencial. Ela pode ser realizada de forma pictórica, fotográfica, escrita, oral, etc.

Intervir comunitariamente nesta abordagem implica também assegurar a sua continuidade, e continuar disponível no relacionamento com as pessoas nele envolvidos, para além de prazos acadêmicos estereotipados e delimitados temporalmente, ainda que a iniciativa da intervenção transformadora deverá emanar dos membros das comunidades com os quais o investigador iniciou a sua intervenção.

Um problema epistemológico ocorre na descrição de intervenções transformadoras, raramente mencionado, mas que consideramos necessário ser ética e deontologicamente debatido. As línguas verbais ocidentais dificultam imenso o trabalho holista, pois assentam em dicotomias ontológicas e lógico-formais, como o princípio de identidade, o do terceiroexcluído, etc. Descrever, por exemplo, intervenções de co-construção simultânea dentro de uma comunidade é extraordinariamente difícil pois deparamos continuamente com o uso linguístico considerado inadequado, ou mesmo errado, por parte da academia. Daí que a escrita surja aparentemente como se tratando de intervenções de tipo construtivista (OLIVEIRA, 2003). Cabe, pois, ao investigador não se esquecer de cumprir um dos requisitos fundamentais da investigação complexa: enunciá-la como pressuposto para que esse viés linguístico possa ser compreendido pelos leitores.

\section{Referências}

ALHADEFF-JONES, M. Revisiting Educational Research Through Morin's Paradigm of Complexity. Complicity: An International Journal of Complexity and Education, v. 6, n. 1, p. 61-70, 2009. 
ALHADEFF-JONES, M. Challenging the Limits of Critique in Education Through Morin's Paradigm of Complexity. Studies in Philosophy and Education, v. 29, n. 5, 477-490, 2010.

ANDER-EGG, E. Repensando la investigación-acción participativa. Vitoria: Gobierno Vasco, 2003.

ANDER-EGG, E. Metodología y práctica de la animación sociocultural. Madrid: Editorial CCS, 2011.

ANDRADE, R. R. El liderazgo comunitário y su importancia em la intervención comunitaria. Psicología para América Latina, n. 25, 57-76, 2013.

ASSIS, S. G et al. Apresentação e divulgação de resultados. In MINAYO, M. C. S.; ASSIS, S. G.; SOUZA, E. R. Avaliação por Triangulação de métodos: Abordagem de Programas Sociais. Rio de Janeiro: Editora Fiocruz, 2005. p. 221-237.

BARROS, J. D. Sobre a noção de Paradigma e seu uso nas ciências humanas. Cadernos de Pesquisa Interdisciplinar em Ciências Humanas, v. 11, n. 98, p. 426444, 2010.

BATESON, G. Steps to an Ecology of Mind. Nova York: Ballantine Books, 1972.

BURBULES, N. Phronesis and complexity. Revista Usal, v. 32, n.1, pp. 11-21, 2020.

CABEZAS, A. B et al. Elementos conceptuales y procedimentales para la intervención orientadora en la comunidad. Revista Electrónica "Actualidades Investigativas em Educación”, v. 17, n. 1, p. 1- 26, 2017.

CAMOZZATO, V. C.; COSTA, M. V. A educação permanente e as impermanências na educação. Educar em Revista, v. Edição Especial, n. 1, p. 153-169, 2017.

CANÁRIO, R. Educação de Adultos: um Campo e uma Problemática. Lisboa: Educa, 1999.

CARR, W.; KEMMIS, S. Becoming Critical. Education, knowledge and action research. Londres: RoutledgeFarmer, 2004.

DELEUZE, G.; GUATTARI, F. Mille Plateaux. Paris: Ed. Minuit, 1980.

DELORS, (1996). Educação: um tesouro a descobrir. São Paulo: Cortez Editora. 
DUPUY, J. P.; DUMOUCHEL, J. P. (orgs.). L'Auto-organisation: de la Physique au Politique. Paris: Seuil, 1983.

ERASMIE, T. (1983). Introdução ao Trabalho de Investigação e Desenvolvimento em Educação de Adultos. Braga: Unidade de Educação de Adultos, Universidade do Minho.

FALS-BORDA, O. (1991). Some basic ingredients. In O. Fals-Borda, \& M. A. Rahman, Action and Knowledge: Breaking the Monopoly with Participatory Action-Research. Londres: Apex Press.

FAURE, E. Aprender a ser. Madrid: Alianza Editorial, 1973.

FILHO, G. L. L. Popper, Kuhn e as Ciências Sociais. Saberes em perspectiva, v. 4, n. 10, p. 9-18, 2014.

FREIRE, P. A pedagogia da indignação: cartas pedagógicas e outros escritos. São Paulo: UNESP, 2000.

GADOTTI, M. A questão da educação formal/não-formal. Droit à l'éducation: solution à tous les problèmes ou problème sans solution?, Sion (Suisse), 18 a 22 de outubro de 2005, 2005.

GADOTTI, M. Educação Popular e Educação ao Longo da Vida. In: NACIF, P. G. S.; QUEIROZ, A. C.; GOMES, L. M. (Coord.). Coletânea de textos CONFINTE A Brasil+6. Brasília: Ministério da Educação, 2016. p. 50-69. GARCÍA, F. J. F.; CHICA, A. A.; VERDÚ, C. P.; FERNÁNDEZ, Ó. A. S. Investigación participativa: métodos y técnicas. Cuenca: PYDLOS ediciones, 2015.

GARCÍA, J. A. C.; SÁNCHEZ, M. G. Educación de Adultos. In: CARRASCO, J. G. Educación de Adultos. Barcelona: Editorial Ariel, 1997. p. 271-277.

GELPI, E. Identidades, conflictos y educación de adultos. Palma: Universitat de les Illes Balears y Diálogos, 1998.

GIRARD, R. Des choses cachées depuis la Fondation du Monde. Paris: Grasset, 1978.

GREENWOOD, D. J.; LEVIN, M. Introduction to Action Research. California: Sage Publications, 2007.

GUERRA, I. Fundamentos e processos de uma sociologia da ação: o planeamento em Ciências Sociais. Cascais: Principia, 2002. 
HERNÁNDEZ-HERNÁNDEZ， F. Presentación: La perspectiva postcualitativa y la posibilidad de pensar en 'otra' investigación educativa. EDUCATIO SIGLO XXI, v. 37, n. 2, p. 11-20, 2019.

HOLLIDAY, O. J. Sistematización de experiencias, investigación y evaluación: aproximaciones desde tres ángulos. Educacion Global Research, n. 1, p. 5670, 2012.

HOMBRADOS-MENDIETA, M. I.; GÓMEZ-JACINTO, L. Empowerment in the community intervention. Intervención Psicosocial, v. 10, n. 1, p. 55-69, 2001.

HUIZINGA, J. Homo Ludens. Boston: Becon Press, 1971.

ILLICH, I. A convivencialidade. Lisboa: Publicações Europa-América, 1976.

ISRAEL, B. A. et al. Health Education and Community Empowerment: Conceptualizing and Measuring Perceptions of Individual, Organizational, and Community Control. Health Education Quarterly, v. 21, n. 2, p. 149-170, 1994.

KEMMIS, S., MCTAGGART, R., \& NIXON, R. The Action Research Planner: Doing Critical Participatory Action Research. Londres: Springer, 2014.

KUHN, T. S. A estrutura das revoluções cientificas. São Paulo: Editora Perspectiva, 1970.

KUHN, T. S. Second thoughts on paradigms. In: SUPPE, F. (Ed.), The Essential Tension, p. 293-319, 1977.

LAPALMA, A. I. El Escenario de la Intervención Comunitaria. Revista de Psicología de la Universidad de Chile, v. X, n. 2, p. 61-70, 2001.

LATORRE, A. La investigación-acción. Conocer y cambiar la práctica educativa. Barcelona: Editorial Graó, 2003.

LEWIN, K. Action Research and Minority Problems. Journal of Social Issues, v. 2, n. 4, p. 34-46, 1946.

LIMA, L. Projecto-Viana (1983-1988). Um ensaio de investigação participativa. Braga: Unidade de Educação de Adultos, Universidade do Minho, 1990.

LIMA, L. Educação ao Longo da Vida. Entre a mão direita e a mão esquerda de Miró. São Paulo: Cortez, 2007.

LIMA, L. A EJA no contexto de uma educação permanente ou ao longo da vida: mais humanos e livres, ou apenas mais competitivos e úteis?. In: 
NACIF, P. G. S.; QUEIROZ, A. C.; GOMES, L. M. (Coord.). Coletânea de textos CONFINTEA Brasil+6. Brasília: Ministério da Educação., 2016a. p. 15-25.

LIMA, L. Revisitação gelpiana da educação permanente: ambiguidades e erosão política de um conceito. Investigar em Educação, v. II, n. 5, p. 53-71, 2016b.

MARCHIONI, M. Comunidad, Participación y Desarrollo. Teoria y metodologia de la intervención comunitaria. Madrid: Editorial Popular, 1999.

MATURANA, H.; VARELA, F. De máquinas y seres vivos: autopoiesis, la organización de lo vivo. Buenos Aires: Lumen, 2003.

MCNIFF, J.; WHITEHEAD, J. All you need to know about Action Research. Londres: Sage Publications, 2006.

MELO, A. A educação permanente, guia de vida e manifesto político nas encruzilhadas da humanidade. Conferência de abertura nas II Jornadas de Educação de Adultos, Coimbra, 27 de janeiro, 2011.

MINAYO, M. C. S. Construção de Indicadores Qualitativos para Avaliação de Mudanças. Revista Brasileira de Educaşão Médica, v. 33, n. 1, p. 83-91, 2009.

MINAYO, M. C. S. Importância da Avaliação Qualitativa combinada com outras modalidades de Avaliação. Saúde \& Transformação Social, v. 1, n. 3, p. 2-11, 2011.

MINAYO, M. C. S. et al. Métodos, técnicas e relações em triangulação. In: MINAYO, M. C. S.; ASSIS, S. G.; SOUZA, E. R. Avaliação por Triangulação de métodos: Abordagem de Programas Sociais. Rio de Janeiro: Editora Fiocruz, 2005.

MORIN, E. From the Concept of System to the Paradigm of Complexity. Journal of Social and Evolutionary Systems, v. 15, n. 4, p. 371-385, 1992.

MORIN, E. Os sete saberes necessários à educação do futuro. São Paulo: Cortez Editora, 2000.

MORIN, E.; CIURANA, E. R.; MOTTA, R. D. Educar na Era Planetária. O pensamento complexo como Método de aprendizagem no erro e na incerteza bumana. Paulo: Cortez Editora, 2003.

NÓVOA, A. Professores. Imagens do futuro presente. Lisboa: Educa. 2009. 
OLIVEIRA, C. C. A Educação como processo auto-organizativo - fundamentos teóricos para uma educação permanente e comunitária. Lisboa: Instituto Piaget, 1999.

OLIVEIRA, C. C. A Lógica da Observação: Contributos para o Esclarecimento do Conceito de Construtivismo. DiaCrítica, n. 17/3, p. 339-350, 2003.

OLIVEIRA, C. C. Contributos Educativos e Comunitários do Movimento Epistemológico da Auto-organização - Um Método Auto-organizativo na formação de educadores de adultos. Educação, v. 1, n. 61, p. 165-180, 2007.

OLIVEIRA, C. C. Educação: Pesquisa, Complexidade e Contemporaneidade. Reflexão e Aç̧ão, v. 16, n. 2, 19-37, 2008.

OLIVEIRA, C. C. O movimento da auto-organização e seus contributos para a educação. Reflexão e Ação, v. 21, n. 2, p. 335-350, 2013 a.

OLIVEIRA, C. C. What Bateson had in Mind About 'Mind'? Biosemiotics, v. 6, n. 3, p. 515-536, 2013b.

OLIVEIRA, C. C. Análise e Desenvolvimento de Conceitos Base no GAIA: Aprendizagem-Educação; Complexidade; Padrão; Narrativa; Metáfora. In: PELLANDA, N; BOETTCHERE, D.; PINTO, M. (coord.), Viver/conbecer na perspectiva da complexidade: experiências de pesquisa. Santa Cruz do Sul: EDUNIC, p. 88-102, 2017.

PERUZZO, C. M. K. Epistemologia e método da pesquisa-ação. Uma aproximação aos movimentos sociais e à comunicação. XXV Encontro Anual da Compós, Universidade Federal de Goiás, 7 a 10 de junho, 2016.

PIAGET, J. Jan Amos Comênio. Recife: Fundação Joaquim Nabuco, Editora Massangana, 2010.

PREDBORSKA, I. E. Morin's Complexity Paradigm in the Context of Informational Challenges to Education. systems. connecting matter, life, culture and technology, v. 1, n. 3, p. 68-82, 2013.

PRIGOGINE, I.; STENGERS, I. Sistema. In: Enciclopédia Einaudi, v. 26; Lisboa: Impr. Nacional/Casa da Moeda, 1993.

RIBEIRO-DIAS, J. A Educação da Nova Humanidade. Porto: Papiro, 2009. 
RORTY, R. Philosophy and the Mirror of Nature. Princeton: University of Princeton Press, 1979.

SAAVEDRA, I. Percursos de conscientizaçãa em contexto de bairro social: um projeto de intervenção com crianças e jovens. 2018. Dissertação (Mestrado em Educação) - Instituto de Educação, Universidade do Minho, Braga [disponível em http://hdl.handle.net/1822/59719].

SÁNCHEZ, M. P. M. Los programas de intervención comunitária desde la perspectiva de sus actores. Liberabit, v. 17, n. 1, p. 59-66, 2011.

SANTOS, B. V. Um discurso sobre as ciências. São Paulo: Cortez Editora, 2008.

SERVA, M. O paradigma da complexidade e a análise organizacional. Revista de Administração de Empresas, v. 32, n. 2, 1992.

STENGERS, I. Les Généalogies de l'Auto-organisation. Cabiers du CREA, n. 8, p. 7-104, 1985.

TOLEDO, R. F.; JACOBI, P. R. Pesquisa-ação e educação: compartilhando princípios na construção de conhecimentos e no fortalecimento comunitário para o enfrentamento de problemas. Educação \& Sociedade, v. 34, n. 122, p. 155-173, 2013.

TRICKETT, E. J.; ESPINO, S. R.; HAWE, P. How are community intervention conceptualized and conducted? An analysis of published accounts. Journal of Community Psychology, v. 39, n. 5, p. 576-591, 2011.

TRIPP, D. Pesquisa-ação: uma introdução metodológica. Educação e Pesquisa, v. 31, n. 3, p. 443-466, 2005.

TUZZO, S. A.; BRAGA, C. F. O processo de triangulação da pesquisa qualitativa: o metafenômeno como gênese. Revista Pesquisa Qualitativa, v. 4, n. 5, p. 140-158, 2016.

ÚCAR, X. Acción comunitaria e intervención socioeducativa en un mundo globalizado. In: ÚCAR, X. (coord.) et al. Enfoques y experiencias internacionales de acción comunitária En España, Israel, Finlandia, Estados Unidos de América y Brasil. Barcelona: GRAO, 2009.

UNESCO. (s.d.). Objetivos do Desenvolvimento Sustentável. Disponível em: https://www.unescoportugal.mne.pt/pt/noticias/objetivos-dedesenvolvimento-sustentavel 
UNRIC - Centro de informação Regional das Nações Unidas para a Europa Ocidental. (2016). Guia sobre o Desenvolvimento Sustentável.

WITTGENSTEIN, L. Culture and V alue. Chicago: University of Chicago Press, 1988.

Submetido em: 11/02/2020

Aceito em: 12/05/2020

Publicado em: 02/07/2020 